\title{
A submersão nas imagens sonoras: o som e suas dimensões reais e imaginárias
}

\section{Damyler Ferreira Cunha}

\section{Resumo:}

Este texto pretende discutir a utilização do ruído fora-de-campo como força expressiva cênica nos filmes: Hamaca Paraguaya (2006), de Paz Encina, La Ciénaga (2001) e La Mujer sin Cabeza (2008), ambos da diretora Lucrécia Martel. A modulação desses ruídos e sua inserção na cena como sons abruptos geram no espectador uma expectativa de algum estado novo que não é revelado pela imagem mostrada, existe uma incongruência entre o que é visto e o que é ouvido na tela.

\section{Palavras Chave:}

Acusmático, fora-de-campo, ruído.

\begin{abstract}
:
This text discusses the use of out-of-the-field noise as an expressive scenic force in Paz Encina's movie Hamaca Paraguaya (2006), and Lucrécia Martel's movies La Ciénaga (2001) and La Mujer sin Cabeza (2008). This noises' modulation and their insertion in the field of action as sudden sounds create to the spectator an expectation of some new situation which is not revealed in the shown image. There is incongruence between what is seen and what is heard on screen.
\end{abstract}

\section{Keywords:}

Acousmatic sound, out-of-the-field, noise.

Ao longo da nossa história, várias formas de arte incorporaram a sonoridade de objetos como elementos de expressão, como um meio de sugestão ou de simbolização. O teórico canadense Murray Schafer, na introdução do seu livro "A afinação do mundo: uma exploração pioneira pela história passada e pelo atual estado do mais negligenciado aspecto do nosso ambiente - a paisagem sonora" definiu o conceito de soundscape ou se preferirmos, paisagem sonora como um projeto de estudo no qual estão relacionadas várias áreas de pesquisa sobre a acústica do mundo, desenvolvidas a partir da investigação das relações entre os homens e os sons do seu ambiente e o que acontece quando esses sons se transformam. Tal conceito implica na questão de como percebemos o ambiente que nos cerca, e conseqüentemente como podemos representá-lo através de uma obra de arte. Para Schafer, sua pesquisa sobre a utilização dos elementos sonoros nas obras artísticas está calcada "sobre os pilares de uma subjetividade romântica com um intuito harmônico já preconizado na história da música apolínea" (SCHAFER, 1997: 21) (1).

No início do século XX, quando se encontra com o cinema, ainda no seu período silencioso, a música e seu intuito harmônico se revelavam como criadores de climas e contextos emocionais, na maioria das vezes sublinhando os gestos dos atores desprovidos da fala. Foi com o advento do cinema sonoro, no final da década de 20 , que a música foi incorporada pelas grandes produções norte-americanas revelando o seu potencial sugestivo e harmônico para enriquecer as suas estratégias narrativas. Pouco a 
pouco, a música se transforma para atender as necessidades do cinema. Do ponto de vista de sua natureza polifônica, a música interage com as imagens a cada momento. Tradicionalmente utilizado para designar algo do universo sonoro, o termo polifonia é utilizado pelo cinema para designar o encontro de vozes simultâneas e independentes que compõe o discurso audiovisual (2). Essas vozes se manifestam de diversas maneiras: pelos diálogos, pelos efeitos sonoros, pela música, e pelos ambientes que compõe o espaço, juntamente com os ruídos. Esses elementos formadores da trilha sonora são relacionados e confrontados ponto a ponto com as imagens em movimento do filme.

A espacialidade, o som polifônico e o texto estão na cena cinematográfica. Estabelecer as relações existentes entre esses elementos no discurso fílmico nos direciona para a retomada de questões relativas ao cenário contemporâneo cinematográfico.

\section{Invisibilidade e audibilidade: os limites da representação}

A dicotomia entre som e imagem sempre incitou a discussão sobre os primórdios da criação de uma imagem realista no cinema. Enquanto no cinema clássico norte-americano, o som é utilizado a partir do pressuposto de códigos naturalistas e tem a função de camuflar ou reforçar a aparente continuidade das imagens, evitando que o espectador se choque com a não linearidade do filme. Paralelamente, a discussão inseriu-se em outro campo e fez surgir uma tradição cinematográfica que retoma uma dramaturgia plástica do cinema e reforça a idéia da utilização do som como contraponto da imagem. Entre esses realizadores, a incorporação de ruídos e sons que tivessem um caráter expressivo na cena contribuiu para o surgimento de outra forma de expressão no cinema.

Interessado em delimitar o campo cinematográfico como arte que só pode ser expressada a partir de suas contradições, Eisenstein desenvolveu a noção de conflito. Para ele, o choque entre a materialidade fílmica e a sua forma racional posicionaria o espectador cinematográfico frente a uma mudança inesperada de uma sensação ou conceito. A arte era vista como revelação das contradições existentes e despertadas no seu espectador. Em sua "Declaração: sobre o futuro do cinema sonoro" (manifesto publicado em 1928, assinado também por Pudovkin e Alexandrov), Eisenstein afirma que uma das materialidades fílmicas que contribui para a criação de uma consciência do espectador em relação ao filme, seria o uso polifônico do som: "Apenas um uso polifônico do som com relação à peça de montagem visual proporcionará uma nova potencialidade no desenvolvimento e aperfeiçoamento da montagem. E apenas uma investida deste tipo levará a criação de um contraponto orquestral das imagens visuais e sonoras" (EISENSTEIN, 2002: 217-220).

O teórico-cineasta parte de duas concepções diferentes quanto à origem do movimento no filme para formalizar o seu conceito de cinema intelectual. Para Eisenstein, os movimentos de fusão e superposição das imagens serão essenciais para a concepção de uma montagem que trabalha com o conflito ou a incongruência entre os elementos fílmicos. O grau de incongruência define a intensidade da tensão, sendo elemento efetivo do ritmo. Para ele, o contraponto acontece com o conflito entre dois tipos de vibrações rítmicas diferentes. Enquanto na música o contraponto está ligado ao motivo da percepção e diferenciação dos sons, no cinema, a síntese está no contraponto entre os sons e a imagem que, por sua vez, estão diretamente relacionados com o tempo e o espaço na construção de uma linguagem fílmica. Uma montagem que fugisse do condicionamento do espaço e do tempo linear ao espectador era o tema em questão para o desenvolvimento da sua proposta de dramaturgia no cinema. As tensões, a não coincidência e as rupturas estabelecem o cinema como lugar de efetuação de fenômenos e procura um espectador que tome consciência do processo de constituição da obra.

Ao escolhermos narrar uma história, não falamos somente de fatos, falamos também de impactos emocionais. Desses impactos emocionais gerados na história, o espectador tem que lidar com uma tensão criada sobre aquilo que nem sempre é explicado ou visto na tela. Neste cinema, o espectador encontra-se implicado na história através da impossibilidade de decifrar as emoções que surgem com as ações dos personagens. A percepção do espectador não é despertada somente para atribuir significados aos estímulos sensoriais pelo que foi visto, mas também pelo que ainda está oculto na obra. Acerca da dimensão material da representação, e dos efeitos que o material cinematográfico propõe ao espectador, a 
teoria do cinema nos anos 80 volta-se para a questão da invisibilidade e da inaudibilidade na representação cinematográfica. Retomando questões adormecidas durante algumas décadas, mas com a atenção voltada para os limites da representação, a dimensão sonora desperta interesse para essa abordagem da teoria cinematográfica, pelo seu caráter sistemático e pela apresentação de formas fixas de intervenção para delimitação do espaço da representação (3).

A procura de um método artístico que solicita ao espectador ir além do aspecto emocional da obra, busca a possibilidade da elaboração de conceitos sobre as coisas no mundo a partir de imagens e sons. $\mathrm{O}$ fragmento por oposição e a abolição de uma representação psicológica mobiliza o espectador para um processo de associações entre o som e a imagem que se opõe a forma corrente de se relacionar com o discurso narrativo clássico. A não-continuidade abre espaço para a desestruturação de hábitos do espectador já preconizados por um cinema de aderência a esse discurso.

\section{Dimensões sonoras e imagéticas}

A manifestação do material fílmico na composição da montagem, como o uso de elipses e a inserção de ruídos abruptos dentro e entre as cenas, inserem ritmo e agilidade nas narrativas. Ela modifica a articulação entre os planos e a composição da unidade espaço-temporal, criando um tempo fílmico que não coincide com o tempo fenomênico. Nos filmes analisados a seguir, são os gestos e a reação dos personagens aos estímulos sonoros que nos possibilitam a localização de um espaço fora-de-campo. A perspectiva subjetiva dá-se pelo fato da experimentação dos sons pelos personagens que reagem a ele. Utilizo aqui o termo personagem, me referindo também à instância do narrador no filme, pois mesmo que o personagem visível na tela não reaja à emissão de uma fonte sonora, os sons podem ter um caráter dramático que modifica a narrativa (4). Neste caso, os ruídos são utilizados como uma força expressiva cênica criando ambigüidade e paradoxos na cena. Não existe uma relação causal entre o que se vê e o que se ouve que garanta a representação nos filmes.

Segundo Pénuela Cañizal, a elipse seria um recurso poético inserido no filme capaz de captar a opacidade do texto fílmico, bem como uma modalidade de ruptura que se manifesta no plano da expressão: "A elipse, definida como omissão de componentes sintáticos, obriga o leitor a lidar com subentendidos, é, portanto, um processo retórico necessário à emergência de ambigüidades acolhedoras do poético. Mas, além disso, a elipse, ao atentar contra a lógica da sintaxe e da gramática fílmicas, engendra ambigüidade tanto no plano do conteúdo quanto no plano da expressão" (PEÑUELA CAÑIZAL, 2007: 189).

No plano da expressão, a elipse é também um recurso que trabalha a disjunção dos elementos fílmicos e caminha no sentido da não homogeneização da história. Os subentendidos, os paradoxos, os conflitos e incongruências ao invés de nos esclarecer o que foi mostrado na cena, nos leva a fundi-las criando mais ambigüidades. O espectador, impossibilitado de controlar a história, ocupa um lugar instável, deslocado do seu lugar tradicional no cinema de narrador onisciente. A flutuação das vozes dispersa o sujeito enunciador na ordem dos discursos, e o situa nas margens que limitam a sua finitude. Mas tal procedimento afetaria a instituição do espectador e o tornaria mais consciente da experiência imersiva no filme?

O deslocamento da sonoridade ou das ações de um filme para um espaço invisível nos remete a questões relacionadas às articulações espaço-temporais no cinema. Diante da experiência da articulação do fora-de-campo, característica do cinema onde o não visto se estrutura em relação ao visto, sua pesquisa nos conduz a questão da "janela aberta para o mundo", já teorizada desde o renascimento até os estudos mais recentes do cinema. No livro O olho interminável, (2005), o teórico francês Jacques Aumont aprofunda questões da linguagem no cinema e analisa como as formas temporais da imagem narrativa estão relacionadas com o espaço onde a representação está ativa. São relativizadas as articulações entre campo e o fora-de-campo como elementos constitutivos do imaginário e da ficcionalização (figura da ausência); e entre o quadro e fora-de-quadro como elementos para a construção da diegese, o espaço da representação.

A noção do quadro, para Jacques Aumont, é antes de tudo o limite de um campo. Seria o lugar 
onde se centraliza a representação cinematográfica, delimitando um espaço e um tempo onde se concentra o imaginário. $\mathrm{O}$ fora-de-campo, assim, seria um lugar potencialmente virtual, podendo ser simplesmente a continuação do que o campo delimita, ou podendo ainda enfraquecê-lo, utilizando-se do vazio como marca de uma ausência na obra. Representar segundo a etmologia da palavra seria "tornar presente" ou "substituir", ou "presentificar", ou "ausentar", é o próprio paradoxo da palavra ausente (5).

Em La Mujer Sin Cabeza (2008), filme da argentina Lucrécia Martel, a quebra de uma lógica narrativa, para a criação de uma narrativa cíclica, é gerada pelos sons cuja origem nem sempre captamos, e por uma câmera colada ao corpo da personagem Verônica (Maria Onetto), a mulher sem cabeça. Neste filme, temos a história de Verônica, que fica perturbada quando acontece um acidente de carro no qual acredita ter matado alguém. A trama é conduzida pelo elemento fantasmático da presença-ausência desse atropelamento, referenciado na cena pelo ruído que o atropelamento causa. A atmosfera de suspense se dá por tudo aquilo que não foi visto, mas foi ouvido por Verônica e pelo espectador do filme. Os sons forade-campo se misturam com a presença de elementos acusmáticos ou virtuais como o som do rádio que a mesma personagem escuta no momento do atropelamento, ou ainda o vídeo do seu casamento no qual outra personagem reconhece o espectro de uma pessoa morta dentro da tela da televisão. Os ruídos, geralmente graves, são apresentados para o espectador em volume mais alto, causando um estranhamento à sua presença na cena, como uma marcação significante do narrador. Tal deslocamento da sonoridade para um espaço fora-de-campo confunde a percepção dos personagens e do espectador do filme. Ao suscitar diferentes possibilidades de sensações, o som seria o elemento capaz de delimitar o espaço mesmo sem sabermos exatamente o que há nele. Então, prestar atenção não seria somente iluminar os dados preexistentes na imagem, seria realizar o contraponto entre o som e a imagem a fim de delimitar uma presença acusmática no cinema. "Em outros termos, não existe no cinema um campo sonoro autônomo, ele está em colaboração com a imagem ao criar suas dimensões reais e imaginárias, que ao mesmo tempo não deixam de ser transbordadas e transgredidas pelo som" (CHION, 2003: 222). Ao conceber a escuta como entendimento, o teórico Michel Chion toma o som como objeto de observação e o examina como elemento da representação cinematográfica vinculada à construção do espaço cênico. Aproximando-se, fenomenologicamente, do teórico e compositor francês Pierre Schaeffer, que constrói sua teoria e dentro dela, o conceito de objeto sonoro como base para a música concreta. Para Schaeffer, em Tratado de los objetos musicales (1998), distinguem-se, genericamente, quatro tipos de escuta: o ouïr, o écouter, o enténdre e o compréendre como acepções lexicografadas do verbo enténdre, uma derivação semântica do significado etimológico no francês "ter a intenção". Nesse contexto, o estudo da voz como elemento musical se amplia e passa a ser considerado a partir das suas possibilidades de estabelecer relações. Em outros termos, na comunicação musical: "Não há fatos puramente objetivos, pois seu ser depende de nossas interpretações. Resgatamos certos fatos do passado, que são vivenciados no presente, e arquitetamos seu futuro a fim de que, neste movimento errático e tentativo dotemos o mundo de sentido. O conhecimento deixa de ser uma única via progressiva para se tornar um campo de relações" (SEINCMAN, 2008: 12).

Esse campo de relações está além da dualidade entre sujeito/objeto. Para Seincman, no livro Estética da comunicação musical (2008), a idéia de um campo sonoro de relações abre espaço para um terceiro lugar, um hiato a ser preenchido onde o individual e o coletivo se retroalimentam continuamente. Como exemplo, temos em La Ciénaga (2001), uma sonoridade que intervém na cena como um elemento de expressão. A presença de ruídos de trovões, taças e pássaros em revoada anunciam uma tempestade que está por vir. Eles flutuam entre os limites do campo e do fora-de-campo e são utilizados expressivamente na cena, a fim de dimensionar o espaço que rodeia a personagem principal em crise, Mecha.

Esse som que surge sem sabermos de onde vem, e que emana no espaço, é definido por Michel Chion (1983: 15) como uma "uma força expressiva que não está nem dentro nem fora do espaço cênico e que vaga em plena liberdade pela superfície da tela". Para Chion, no artigo "Les trois frontieres" (2003: 221), o som delimita o espaço com as vozes: que podem habitar o campo (in), as suas margens (fora-decampo) ou que são dirigidas ao proscênio (som off cuja fonte não captamos, revelando uma presença 
acusmática, um fenômeno pelo qual tem-se a impressão de ter ouvido algum som, criando uma imagem mental abstrata). Em La Cienága, os limites espaciais serão transgredidos pela sonoridade das cenas. Nesta paisagem, os ruídos se tornam um elemento estrutural da composição sonora do filme, e modificam a articulação entre os planos suprimindo ou deslocando a ação realizada pelos personagens. Além da utilização da elipse que modifica a articulação entre os planos, e da composição de uma unidade espaçotemporal, os personagens são mostrados como seres inertes, pois nem sempre reagem as ações que se desenrolam na cena, incitando mais ambigüidade. Assim, os elementos sonoros são reordenados para que surja um ritmo crescente da situação de tensão. Esse ritmo apresenta-se com a modulação de ruídos pela variação da altura, da intensidade e da frequiência, mudando sua tonalidade e criando um contraste sonoro, para que num rompante, surjam censuras no ritmo, e o ouvinte tenha que lidar com o vazio que se cria na tela.

A experiência do vazio como marca de uma ausência, e da não-significação nos remete a consciência daquilo que já foi vivido fisicamente pelos personagens e, consequientemente, pelo espectador. Ora, se os sons dentro do quadro, assim como as imagens, são concêntricos, os sons fora-dequadro podem ser excêntricos, e também se transformar em cacofonia, já que não identificamos sua fonte na imagem vista. Para Blanchot, a linguagem levada aos seus limites desencadeia uma experiência do vazio que se desdobra em rumores, "negando assim seu próprio discurso, fazendo-se passar fora de si, despojando os enunciados do seu querer-dizer, uma ausência que se retira para mais longe de si mesma" (6) (BRUNO, 2007: 153).

Em La Ciénaga e La Mujer Sin Cabeza, as histórias retratadas acontecem na mesma região do noroeste argentino, na província de Salta. Lucrecia Martel nos apresenta um lugar e, desta maneira, o mundo de seus personagens. A maneira de conceber o real nasce sob a forma do conflito, sob o signo da violência e do atrito de vibrações diferentes em som e imagem. Algo precisa desestabilizar os caminhos perceptivos naturalizados, fazendo surgir rompimentos. Somos levados a observar esses personagens com um olhar que nos indica o além. Olhar além, de um lugar marcado pela indiferença, estagnação e apatia das famílias das duas protagonistas dos filmes com uma imagem que privilegia o detalhe, utilizando a câmera em primeiro, ou primeiríssimo plano. Essas duas mulheres, Mecha (La Cienága) e Verônica ( $L a$ Mujer Sin Cabeza) vivem a fatalidade de um acontecimento, que detona numa crise cheia de lapsos, ausências, e angústias sobre o esquecimento do seu passado. Há um paralelismo entre a situação das personagens: a decisão de esquecer o acontecido ao apagá-lo, ocultando os fatos do seu entorno.

Nessa contraposição, entre revelar e ocultar, a polifonia audiovisual caminha, pouco a pouco, no sentido de gerar algum tipo de impacto no espectador. Neste caso, é o estranhamento que desperta a nossa atenção e cria memória. A utilização do silêncio, as conversas em tons baixos e os sussuros entre os personagens enfatizam um paradoxo ao ambiente externo repleto de informações sonoras subentendidas.

Outro exemplo da invisibilidade utilizada em contraposição a audibilidade dos sons, e do deslocamento da sonoridade para o espaço fora-de-campo, é o filme Hamaca Paraguaya (2006), primeiro longa-metragem da cineasta paraguaia Paz Encina. Com a co-produção argentina da produtora Lita Stantic (responsável pela produção dos filmes de Lucrecia Martel), e uma equipe técnica de som, formada pelos mesmos profissionais que realizaram os filmes La Ciénaga e La Mujer Sin Cabeza. Hamaca Paraguaya parece estender essa presença acusmática dos sons que interferem na construção da narrativa. Além dos ruídos, temos a inserção de uma voz sem corpo cuja presença-ausência será o elemento que articula o relato. Esta voz é do filho do casal de idosos que vemos na tela.

Os diálogos em guarani, aparecem sempre em voz off ou fora-de-campo, pois nunca vemos os personagens moverem seus lábios. Falam sobre a partida de seu filho para a Guerra do Chaco (entre Bolívia e Paraguai, em 1935) e sobre a espera de seu retorno. Em alguns momentos, ouvimos a voz do filho que discute com os pais sua partida para a Guerra. A confusão entre o tempo passado e o presente causa um efeito perturbador, que ressalta uma incongruência, uma voz dessincronizada, que pode expressar um diálogo interior dos personagens, ou ainda, um diálogo que acontece em outro tempo, diferente do que a imagem nos mostra. Acerca da ambigüidade, segundo Seincman, na cadeia comunicativa existe uma dialética própria entre memória e esquecimento. Para ele, a experiência estética, 
qualquer que seja, envolve uma seqüência de lapidações de seu autor e intérprete que funcionam da seguinte maneira: "A cadeia comunicativa requer técnicas que consubstanciem, por um lado, os meios de expressar-se (sair de si, atuar de dentro pra fora, do interior para o exterior), os quais por sua vez, irão garantir as possibilidades de impressionar-se (voltar a si, sofrer a ação de fora pra dentro, do exterior ao interior). Expressar-se e impressionar-se retroalimentam-se continuamente: se o primeiro associa-se a memória de si, o segundo relaciona-se com o esquecimento de si" (SEINCMAN, 2008: 36).

É desse desdobramento do espectador cinematográfico, entre ouvinte e intérprete da obra, que na comunicação audiovisual cria-se um texto expressivo. Neste caso, ouvir e interpretar também poderia ser completar as lacunas do texto com as informações sugeridas ou subentendidas pelo próprio texto. Esteticamente, não há impressões sonoras que não sejam acompanhadas das impressões visuais ou táteis, já que sentimos com todos os sentidos. Essas impressões são variáveis conforme as nossas condições culturais e sociais de ouvir. O recorte sonoro, e seu direcionamento no espaço não pode ser concebido como o olhar. Como observou Michel Chion (1983: 80), se considerarmos a natureza omnidirecional do som e da escuta, ele se propaga por todos os lados. São os gestos e as reações dos personagens, ou de um narrador que nos indicam a localização de um som. Aliados, os sons e gestos dão tonalidade, variação e ritmos a uma imagem no cinema. E mesmo que nenhum personagem reaja para localizarmos a fonte de ruído, a forma como este é apresentado também pode influenciar na história que o espectador percebe.

Nos dias atuais, diversas são as propostas de união dos sons e das imagens no cinema que fogem de um padrão que repete antigos códigos naturalistas, segundo os quais temos a narrativa centralizada nos diálogos e no uso de músicas e ruídos como elementos redundantes em relação ao que a imagem já nos informa. Entretanto, cada vez mais, o espaço dado aos sons e aos ruídos cresce no cinema, sejam elas forças expressivas na construção de narrativas que provocam rupturas, preservação ou renovação de estilos.

Os modos de construção da narrativa dos filmes escolhidos para realização deste artigo estão relacionados à quebra de uma lógica narrativa, à criação de um tempo cíclico e a um espaço de flutuação do discurso entre os limites do campo e do fora-de-campo fílmico. Os sons que flutuam entre os espaços off, in e fora-de-campo produzem um impacto constante no espectador por não localizarem na imagem os acontecimentos no momento mesmo em que eles se desenrolam. A voz não afirma o gesto, perturba o espectador e o impede de embarcar na história, reconduzindo-o ao tempo da experiência das sensações fílmicas.

Nesses filmes, os sons que habitam o fora-de-campo emanam uma aparente flutuação dos discursos na narrativa ao descentralizar os diálogos dos personagens. A inter-relação entre o texto, o som polifônico e a espacialidade constrói a apresentação de uma história que não pode ser explicada na tela, mas é capaz de ser sentida e entendida pelo espectador. O olhar empreendido à cena ultrapassa os sentidos visuais e toma outras dimensões sensoriais.

Por outro lado, a inserção de novos profissionais de som na produção cinematográfica tem proporcionado novas formas de construção de uma narrativa que utiliza os elementos sonoros de formas inovadoras, as quais concretizaram alternativas ao modelo narrativo dominante da centralização do diálogo (7). O desenvolvimento de um planejamento técnico e estético sonoro nas várias etapas de construção do filme unifica o trabalho de pós-produção com o desenvolvimento do roteiro, da préprodução e das filmagens.

Finalmente, é importante repensar o cinema latino a partir de seus processos de criação, produção e difusão atuais para buscar romper opiniões pré-concebidas, tanto em relação às heranças latinas que carrega quanto à sua contemporaneidade. Dar visibilidade para o outro é buscar marcas deste outro em si mesmo.

\section{Bibliografia:}


ALBERA, François. Eisenstein e o Construtivismo Russo - A dramaturgia da forma em "Stuttgart" . São Paulo: Cosac Naify, 2002.

AUMONT, Jacques. O olho interminável. Cinema e pintura. São Paulo: Cosac Naify, 2004.

BRUNO, Mário. "Foucalt e Blancho. Da analítica da finitude a experiência do fora". In: QUEIROZ, André; MORAES, Fabiana de; CRUZ, Nina Velasco (org.). Barthes/Blanchot: um encontro possível? Rio de Janeiro: 7Letras, 2007.

CASETTI, Francesco. Teorias del cine: 1945-1990. Madrid: Cátedra, 1994.

CHION, Michel. "Les trois frontières". In: poétique. Paris: Essais - Cahiers du Cinema, 2003, pp.221-225.

Un art sonore, le cinèma: histoire, esthétique,

. Guide des objets sonores: Pierre Schaeffer et la recherce

musicale. Paris: Buchet/Chastel, 1983.

CAÑIZAL, Eduardob Peñuela. "Manifestação de recursos poéticos em dois filmes do Cinema Novo". In: MACHADO JR., Rubens; SOARES, Rosana; ARAÚJO, Luciana (orgs.). Estudos de Cinema VIII SOCINE. São Paulo: Annablume, 2007, pp.189-200.

CARRASCO, Ney. Sygkhronos: a formação da poética musical do cinema. São Paulo: Via Lettera/Fapesp, 2003.

EISENSTEIN, S. M.; PUDOVKIN, V. I.; ALEXANDROV, V. G. "Declaração Sobre o futuro do cinema sonoro". A forma do filme. São Paulo: Jorge Zahar, 2002.

MACHADO, Arlindo. O sujeito na tela: modos de enunciação no cinema e no ciberespaço. São Paulo: Paulus, 2007.

PONTY, Merleau. A estrutura do comportamento. Belo Horizonte: Interlivros, 1975 (texto original publicado em 1942).

SCHAEFFER, Pierre. Tratado de los objetos musicales. Espanha: Alianza Editorial, 1998.

SCHAFER, Murray. A afinação do mundo: uma exploração pioneira da história passada e pelo atual estado do mais negligenciado aspecto do nosso ambiente - a paisagem sonora. São Paulo: Editora Unesp, 1997.

SEINCMAN, Eduardo. Estética da comunicação musical. São Paulo: Via Lettera, 2008.

\section{Notas:}

Trabalho apresentado na I Jornada Discente do Programa de Pós-Graduação em Meios e Processos Audiovisuais da Escola de Comunicações e Artes da Universidade de São Paulo (ECA-USP), realizada em novembro de 2010.

(1) Para maiores esclarecimentos sobre a subjetividade romântica e a história da música apolínea, ler o capítulo 1 do livro A afinação do mundo: uma exploração pioneira da história passada e pelo atual estado do mais negligenciado aspecto do nosso ambiente - a paisagem sonora, de Murray Schafer (1997).

(2) Ver "Overture" do livro Sygkhronos: a formação da poética musical do cinema, de Ney Carrasco (2003).

(3) Ver CASETTI, Francesco. Teorias del cine: 1945-1990, Madrid: Cátedra, 1994, p.267.

(4) Sobre o sujeito da enunciação no cinema, ver o livro de Arlindo Machado O sujeito na tela: modos de enunciação no cinema e no ciberespaço (2007).

(5) Do capítulo "Da cena à tela, ou o espaço da representação". In: AUMONT, Jacques. O olho interminável (2005), p.152.

(6) BRUNO, Mário. "Foucalt e Blanchot. Da analítica da finitude à experiência do fora". In: QUEIROZ, André; MORAES, Fabiana de; CRUZ, Nina Velasco (org.). Barthes/Blanchot: um encontro possível?. Rio de Janeiro: 7Letras, 2007.

(7) Sobre a centralização do diálogo na história do cinema clássico, ver Jacques Aumont em $O$ olho interminável (2004), p.125. 


\section{Mini Currículo :}

Graduada em comunicação social (rádio e televisão) pela Universidade Federal de Goiás. Mestranda no programa de Pós-Graduação em Meios e Processos Audiovisuais da Escola de Comunicaçôes e Artes da USP. 